INTERNATIONAL RESEARCH JOURNAL OF PHARMACY

\title{
FORMULATION AND EVALUATION OF TASTE MASKED ORODISPERSIBLE TABLETS OF AMLODIPINE BESYLATE BY DIRECT COMPRESSION
}

B. Sree Giri Prasad ${ }^{1}$, V.R.M Gupta ${ }^{2}$, N. Devanna ${ }^{3}$, N. Siva Subramanian ${ }^{1}$, CH. Naveen Kumar ${ }^{1}$, CH. Maheswar Reddy $^{1}$

${ }^{1}$ Teegala Krishna Reddy College of Pharmacy, Ranga Reddy, A.P., India

${ }^{2}$ Pulla Reddy Institute of Pharmacy, Hyderabad, A.P., India

${ }^{3}$ Jawaharlal Nehru Technological University, Anantapur, A.P, India

*Corresponding Author Email: prasad.bsreegiriprasad@gmail.com

Article Received on: 11/03/13 Revised on: 06/04/13 Approved for publication: 17/05/13

DOI: $10.7897 / 2230-8407.04728$

IRJP is an official publication of Moksha Publishing House. Website: www.mokshaph.com

(c) All rights reserved.

\section{ABSTRACT}

The purpose of this investigation was undertaken to design a simple, rapid, cost effective and highly efficient process to fabricate intensely bitter taste of Amlodipine Besylate by complexing drug with Aminoalkyl methacrylate copolymer (Eudragit EPO) in different ratios by Hot-Melt Extrusion method. Taste masked complex were analyzed with FTIR, DSC and XRD. DCP were tested for Hardness, Thickness, Weight Variation, Drug Content, Water absorption and In vitro Dispersion Test in Simulated Salivary Fluid $\mathrm{pH}$ 6.8. Taste masked granules were directly compressed into tablets using Kollodion CL and Croscarmellose Sodium (Ac-Di-Sol) as superdisintegrants. Tablets of batch $\mathrm{F}_{6}$ containing mannitol and 6\% wt/wt of Kollodion $\mathrm{CL}$ showed faster disintegration with in $24 \mathrm{sec}$ and drug release $\left(\mathrm{t}_{90}, 180 \mathrm{sec}\right)$ at Phosphate Buffer $\mathrm{pH} 6.8$. The observed polymer interaction and reduced crystallinity may be reason for increased dissolution rate. Thus results conclusively demonstrate successful masking of taste, disintegration and dissolution of the formulated tablets.

Keywords: Drug Polymer Complex, Hot Extrusion Method, Amlodipine Besylate, Kollodion CL, Croscarmellose Sodium, Oro Dispersible Tablets.

\section{INTRODUCTION}

Recent advances in novel drug-delivery system aims to enhance the safety and efficacy of the drug molecule by formulating a dosage form being convenient for the administration. Difficulty in swallowing (i.e. dysphagia) is experienced by patients such as paediatrics, geriatric, bedridden, disabled, mentally ill, including motion sickness and sudden episodes of allergic attacks, hence resulting in higher incidence of noncompliance and ineffective therapy ${ }^{1}$. In order to solve this problem and improve patient acceptance and compliance, the development of solid dosage forms that disintegrate rapidly or dissolve even when taken orally without water is being undertaken. oral route of drug administration have wide acceptance, up to $50-60 \%$ of solid dosage forms are popular because of natural, uncomplicated, convenient, ease of administration, accurate dosage, selfmedication, pain avoidance and most importantly patient compliance. The most popular solid dosage forms being tablets and capsules, one important drawback of these dosage forms for patient is the difficulty to swallow. Swallowing of solid dosage forms like tablets and capsules and improper dosing of suspension and emulsion may produce difficulty for young children because of incomplete development of muscular and nervous system and elderly patients suffering from dysphasia, Parkinson's disorder and tremor. Other groups that may experience problems using conventional oral dosage forms include the mentally ill, the developmentally disabled patients, patients who are uncooperative, or on reduced liquid intake plans or nauseated, patients having a persistent cough or a gag-reflex and travellers who may not have access to water ${ }^{2}$. Oral fast-disintegrating dosage forms (tablet or a capsule) are a relatively novel dosage technology that involves the rapid disintegration or dissolution of the dosage form into a solution or suspension in the mouth without the need for water ${ }^{3-5}$. The dosage form begins to disintegrate immediately after coming into contact with saliva, with complete disintegration normally occurring within $30-50 \mathrm{~s}$ after administration ${ }^{6}$. The solution containing the active ingredients is swallowed and the active ingredients are then absorbed through the gastrointestinal epithelium to reach the target and produce the desired effect. Tablet is the most widely used dosage form because of its convenience in terms of self-administration, compactness and ease in manufacturing ${ }^{7}$. Orally disintegrating tablets are also called as Orodispersible tablets, quick-disintegrating tablets, mouthdissolving tablets, fast-disintegrating tablets, fast dissolving tablets, rapid-dissolving tablets, porous tablets and rapid melts. However, of all the above terms, the United States Pharmacopoeia (USP) approved these dosage forms as Orodispersible tablets (ODTs). Recently, the European Pharmacopoeia has used the term Orodispersible tablets for tablets that disperse readily and within $3 \mathrm{~min}$ in the mouth before swallowing. The United States Food and Drug Administration define ODT as "a solid dosage form containing medicinal substance or active ingredient which disintegrates rapidly usually within a matter of seconds when placed upon the tongue." The disintegration time for ODTs generally ranges from several seconds to about a minute ${ }^{8}$. Other advantages of ODTs that have been investigated are their potential to increase the bioavailability of poorly water soluble drug through enhancing the dissolution profile of the drug $^{9}$. Moreover, pharmaceutical companies also have commercial reasons for formulating ODTs. As a drug reaches the end of its patent, the development and formulation of the drug into new dosage forms allow pharmaceutical companies to extend the patent life and "market exclusivity" ODTs could be prepared using various techniques such as tablet moulding, spray drying, sublimation, lyophilization, solid dispersion, or addition of disintegrants ${ }^{11-15}$. The basic approach to the development of ODTs is the use of superdisintegrants such as Croscarmellose sodium and sodium starch glycolate. Another approach used in developing ODTs is maximizing the pore structure of the tablet matrix. Freeze drying and vacuum drying techniques have been tried by researchers to maximize the pore structure of the tablet matrix ${ }^{16-18}$. However, freeze drying is 
cumbersome and yields a fragile and hygroscopic product. Vacuum drying along with the sublimation of volatilizable ingredient has been employed to increase tablet porosity. While in designing dispersible tablets, it is possible to achieve effective taste masking as well as a pleasant feel in the mouth. The main criterion for ODTs is the ability to disintegrate or dissolve rapidly in saliva of the oral cavity in 15 to $60 \mathrm{~s}$ and have a pleasant mouth feel. To improve the quality of life and treatment compliance, great efforts have been made to develop fast-disintegrating tablets (FDTs) in the oral cavity, using jelly, water-absorbing and swellinggelated materials or water-soluble polymers ${ }^{19}$. However, of all the above terms, United States pharmacopoeia (USP) approved these dosage forms as ODTs. Recently, European Pharmacopoeia has used the term Orodispersible tablet for tablets that disperses readily and within $3 \mathrm{~min}$ in mouth before swallowing. United States Food and Drug Administration (FDA) defined ODT as "A solid dosage form containing medicinal substance or active ingredient which disintegrates rapidly usually within a matter of seconds when placed upon the tongue." The disintegration time for ODTs generally ranges from several seconds to about a minute ${ }^{20}$.

\section{MATERIALS}

Amlodipine Besylate was chosen as an active ingredient and it was gift sample from Dr. Reddy's Laboratories, Hyderabad, Andhra Pradesh, India. Eudragit EPO, Mannitol, Kollidon CL, Croscarmellose Sodium, Aspartame and Magnesium stearate were purchased from colorcon, Mumbai, India. All other reagents were of analytical grade.

\section{METHOD}

\section{Preparation of Drug - Polymer Complex}

The drug polymer complex (DPC) was prepared by Hot- melt Extrusion using different ratio of Amlodipine Besylate and Eudragit EPO (1:1 and 1:2). Initially, Amlodipine Besylate is passed through \#60 sieves. Later Eudragit EPO is melted at a temperature of $100{ }^{0} \mathrm{C}$. After the complete melting of polymer the drug is incorporated slowly with continuous stirring. Then after uniform mixing the mixture is cooled, finely grounded and passed through \#30 sieve followed by passing through \# 60 sieves.

\section{Formulation of Oral Dispersible Tablets}

Oral dispersible tablets were prepared by Direct Compression Method. Initially, Amlodipine Besylate and Drug Polymer complex is weighed individually for each formulation. Kollidon CL, Cross carmellose sodium, Mannitol, Aspartame is passed through sieve No. 60 and individually weighed for each formulation (Table 1). These are mixed with DPC on polyethylene paper. Similarly, Aerosil and Magnesium sterate are individually passed through sieve No. 60 and individual quantities are weighed and mixed thoroughly with the above mixture and finely mixed for 10 Minutes. The mixed blend was punched into individual biconvex tablets weighing $100 \mathrm{mg}$ on a multi punch tablet machine using 6 $\mathrm{mm}$ punch for compression. 20 tablets were punched of each formulation. Similarly, blank tablets without containing Eudragit EPO are weighed and punched as per formulation FB6 and SB6.

\section{Evaluation \\ Characterization of drug-polymer complex \\ Fourier Transform Infrared (FTIR) Spectroscopy}

FTIR spectra were obtained on Shimadzu FTIR Model 8400-

$\mathrm{S}$ spectrometer. The Spectra was recorded as a dispersion of the sample in Potassium Bromide in IR disk ( $2 \mathrm{mg}$ sample in $200 \mathrm{mg} \mathrm{KBr}$ ) with the scanning range of 400 to $4000 \mathrm{~cm}^{-1}$ and the resolution was $1 \mathrm{~cm}^{-1}$.

\section{X-Ray Diffraction (XRD) Studies}

X-ray Diffraction analysis was carried out to evaluate the degree of crystallinity. The pure Amlodipine Besylate, pure Eudragit EPO, and drug polymer complex (1:1) were subjected to powder XRD (P.W. 1729, X-Ray Generator, Philips, Netherland) at $2 \Theta$ angles between 20 and $38^{\circ}$ in increments of $0.40^{21}$.

\section{Drug Content}

DPC equivalent to $10 \mathrm{mg}$ of drug was stirred by using magnetic stirrer with $100 \mathrm{ml}$ of Methanol for 60 minutes, till the entire drug leached out from complex, than the solution was filter through whatman filter paper. Further solution was diluted with methanol and the drug content was determined spectrophotometrically at $239 \mathrm{~nm}^{21}$.

\section{Characeterization of Powder Blend}

\section{Angle of Repose}

Angle of repose was determined using funnel method. The blend was poured through a funnel that can be raised vertically until a maximum cone height (h) was obtained. Radius of the heap (r) was measured and angle of repose $(\theta)$ was calculated using the following formula ${ }^{22-24}$,

$$
\tan \theta=\mathrm{h} / \mathrm{r}
$$

\section{Bulk Density}

Apparent bulk density ( $\rho b)$ was determined by pouring the blend into a graduated cylinder. The bulk volume $(\mathrm{Vb})$ and weight of the powder (M) was determined. The bulk density ( $\rho$ b) was calculated using following formula,

$$
\rho b=V b / M
$$

\section{Tapped Density}

The measuring cylinder containing a known mass of blend (M) was tapped for a fixed time (100 tapings). The minimum volume $(\mathrm{Vt})$ occupied in the cylinder and weight of the blend was measured. The tapped density $(\rho t)$ was calculated using following formula,

$$
\rho t=V t / M
$$

\section{Compressibility Index}

The simplest method of measurement of free flow of powder is compressibility, an indication of the ease with which material can be induced to flow and is given by compressibility index (I) which is calculated as follows,

$$
\mathrm{I}=\{(\rho \mathrm{t}-\rho \mathrm{b}) / \rho \mathrm{t}\} * 100
$$

The value below $15 \%$ indicates a powder which usually gives rise to excellent flow characteristics, whereas above $25 \%$ indicate poor flow ability.

\section{Hausner's Ratio (H)}

This is an indirect index of ease of powder flow. It is calculated by the following formula,

$$
\mathrm{H}=\rho \mathrm{t} / \rho \mathrm{b}
$$

Lower Hausner's ratio $(<1.25)$ indicates better flow properties than higher ones $(>1.25)$. 
Post Compression Evaluation

\section{Uniformity of Weight}

The test was carried out according to the US pharmacopoeia. 20 tablets, of each formulation were individually weighed and the mean of tablet weights was calculated. Results are presented as mean value ${ }^{25-28}$.

\section{Hardness}

The fracture strength, which is defined as the force required breaking a tablet by radial compression was measured with a tablet hardness tester ${ }^{25-28}$ (Monsanto hardness tester).

\section{Friability}

The friability of sample of six tablets ware measured using a Roche Friabilator (Electrolab EF-2, USP). Six pre-weighed tablets were rotated at $25 \mathrm{rpm}$ for 4 minutes. The tablets were then reweighed after removal of fine's using 60 mesh screens and the percentage of weight loss was calculated ${ }^{25-28}$.

$$
\% \text { Friability }=(\text { Loss in weight } / \text { Initial weight }) \times 100
$$

\section{Wetting Time}

The wetting time of the tablets has been measured using a simple procedure. Five circular tissue papers of $10 \mathrm{~cm}$ diameter are placed in a petridish with a $10 \mathrm{~cm}$ diameter. Ten millimetres of water- containing Eosin, a water-soluble dye, is added to petridish. A tablet is carefully placed on the surface of the tissue paper. The time required for water to reach upper surface of the tablet is noted as a wetting time ${ }^{25-}$ 28

\section{(\%) Water Absorption Ratio}

A piece of tissue paper folded twice was placed in a small petridish (Internal Diameter $=6.5 \mathrm{~cm}$ ) containing $6 \mathrm{ml}$ of water. A tablet was placed on the paper and the time required for complete wetting was then measured. The water absorption ratio $(\mathrm{R})$ was determined using the following equation. ${ }^{25-28}$

$$
\mathrm{R}=100(\mathrm{Wa}-\mathrm{Wb}) / \mathrm{Wb}
$$

Where, $\mathrm{Wb}$ is the weight of the tablet before water absorption and $\mathrm{Wa}$ is the weight of the tablet after water absorption.

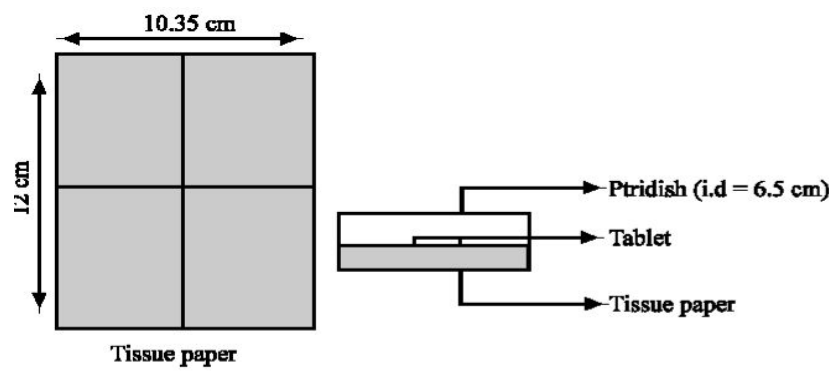

Figure 1

\section{Content Uniformity}

For the content uniformity test, ten tablets were weighed and pulverized to a fine powder, a quantity of powder equivalent to $10 \mathrm{mg}$ of Amlodipine Besylate was extracted in $10 \mathrm{ml}$ of methanol and liquid was filtered $(0.22 \mu \mathrm{m}$ membrane filter disc (Millipore Corporation). The drug content was determined by measuring the absorbance at $239 \mathrm{~nm}$ (using UV Spectrophotometer, Shimadzu 1800) after appropriate dilution with methanol. The drug content was determined using standard calibration curve. The mean percent drug content was calculated as an average of three determinations ${ }^{25-28}$.

\section{Taste Evaluation}

The objective of this study is to conduct and evaluate the Palatability of different formulations of Amlodipine Besylate oral disintegrating tablets. Amlodipine Besylate ODT was a new development; reference product is not available for ODT in market for this product for comparison of the taste evaluation. Total 16 formulations were selected for taste evaluation study, 14 test formulations (Table 1), one positive control (Placebo for Amlodipine Besylate) and one is negative control (Placebo for Taste enhancers like aspartame and peppermint flavour). All formulations (formulation code) were randomized. Each randomization order was assigned with sequence code. For this study were selected 6 healthy human volunteers 3 male and 3 Female of age around 21-22 years and were assigned volunteer code. All the 6 volunteers were evaluated all eight formulations as per the randomization order. Each of the formulations were transferred to HDPE bottles and labelled only with formulation code. Palatability evaluation feedback format prepared and submitted to each individual volunteer and were provided with instructions before starting study. One tablet of each formulation was given to volunteer for palatability study evaluation. The time interval between evaluations of each test formulation in the same volunteer was $30 \mathrm{~min}$, at after evaluated each formulation, one half of a bread slice was given to each volunteer followed by half glass of water and cocoa powder for neutralizing the taste buds. After completion of the study, data was compiled and evaluated the formulations and allotted the rank for all formulation, based on the average value of the each formulation ${ }^{29}$.

\section{In vitro dispersion time (with simulated salivary fluid)}

This test is performed to ensure disintegration of tablets in the salivary fluid, In vitro dispersion time was measured by dropping a tablet in a Petri dish containing $6 \mathrm{ml}$ of simulated salivary fluid of $\mathrm{pH} 6.8 .^{25-28}$

\section{In vitro Drug Release Study}

In-vitro dissolution studies of the fast disintegrating tablets of Amlodipine Besylate formulation were performed according to USP XXIII Type-II dissolution apparatus (Electrolab, model TDT-06N) employing a paddle stirrer at $50 \mathrm{rpm}$ using $900 \mathrm{ml}$ of $\mathrm{pH} 6.8$ phosphate buffer at $37 \pm 0.5^{\circ} \mathrm{C}$ as dissolution medium. One tablet was used in each test. Aliquots of the dissolution medium $(10 \mathrm{ml})$ were withdrawn at specific time intervals and replaced immediately with equal volume of fresh medium. The samples were analyzed for drug content by measuring the absorbance at $239 \mathrm{~nm}$. Drug concentration was calculated from the standard calibration curve and expressed as cumulative percent drug dissolved $^{25-28}$.

\section{Statistical Analysis}

The results were analyzed by two tailed Student's t-test using the Graph Pad Instat Software (GPIS; Version: 1.13) 
B. Sree Giri Prasad et al. Int. Res. J. Pharm. 2013, 4 (7)

Table 1: Formulation of Amlodipine Besylate Orodispersible Tablets

\begin{tabular}{|c|c|c|c|c|c|c|c|c|c|c|c|c|c|c|}
\hline Ingredients & F1 & F2 & F3 & F4 & F5 & F6 & FB6 & S1 & S2 & S3 & S4 & S5 & S6 & SB6 \\
\hline Amlodipine Besylate & 10 & 10 & 10 & 10 & 10 & 10 & 10 & 10 & 10 & 10 & 10 & 10 & 10 & 10 \\
\hline Eudragit EPO & 10 & 10 & 10 & 10 & 10 & 10 & - & 10 & 10 & 10 & 10 & 10 & 10 & - \\
\hline Kollidone CL & 1 & 2 & 3 & 4 & 5 & 6 & 6 & - & - & - & - & - & - & - \\
\hline Croscarmellose sodium & - & - & - & - & - & - & - & 1 & 2 & 3 & 4 & 5 & 6 & 6 \\
\hline Mannitol & 77.8 & 76.8 & 75.8 & 74.8 & 73.8 & 72.8 & 71.8 & 77.8 & 76.8 & 75.8 & 74.8 & 73.8 & 72.8 & 83.8 \\
\hline Aspartame & - & - & - & - & - & - & 4 & - & - & - & - & - & - & 4 \\
\hline Mg. Sterate & 0.6 & 0.6 & 0.6 & 0.6 & 0.6 & 0.6 & 0.6 & 0.6 & 0.6 & 0.6 & 0.6 & 0.6 & 0.6 & 0.6 \\
\hline Aerosil & 0.6 & 0.6 & 0.6 & 0.6 & 0.6 & 0.6 & 0.6 & 0.6 & 0.6 & 0.6 & 0.6 & 0.6 & 0.6 & 0.6 \\
\hline Total Weight & 100 & 100 & 100 & 100 & 100 & 100 & 100 & 100 & 100 & 100 & 100 & 100 & 100 & 100 \\
\hline
\end{tabular}

Table 2: Characterisation of Powder Blend

\begin{tabular}{|c|c|c|c|c|c|}
\hline Formulation & Angle of repose & Bulk Density & Tapped Density & Percent compressibility Index & Hausner's Ratio \\
\hline F1 & $23.29 \pm 0.01$ & $0.51 \pm 0.01$ & $0.676 \pm 0.01$ & $23.71 \pm 0.01$ & $1.31 \pm 0.01$ \\
\hline F2 & $22.47 \pm 0.02$ & $0.45 \pm 0.01$ & $0.526 \pm 0.01$ & $14.41 \pm 0.01$ & $1.16 \pm 0.01$ \\
\hline F3 & $20.18 \pm 0.01$ & $0.45 \pm 0.03$ & $0.543 \pm 0.04$ & $15.6 \pm 0.02$ & $1.18 \pm 0.01$ \\
\hline F4 & $21.8 \pm 0.03$ & $0.49 \pm 0.01$ & $0.555 \pm 0.01$ & $1.76 \pm 0.02$ & $1.13 \pm 0.02$ \\
\hline F5 & $23.89 \pm 0.01$ & $0.43 \pm 0.02$ & $0.515 \pm 0.03$ & $15.83 \pm 0.01$ & $1.19 \pm 0.01$ \\
\hline F6 & $23.8 \pm 0.02$ & $0.41 \pm 0.01$ & $0.495 \pm 0.01$ & $14.91 \pm 0.02$ & $1.18 \pm 0.02$ \\
\hline S1 & $23.12 \pm 0.02$ & $0.43 \pm 0.01$ & $0.515 \pm 0.02$ & $15.74 \pm 0.01$ & $1.17 \pm 0.01$ \\
\hline S2 & $23.19 \pm 0.02$ & $0.46 \pm 0.01$ & $0.549 \pm 0.01$ & $14.03 \pm 0.01$ & $1.16 \pm 0.01$ \\
\hline S3 & $22.86 \pm 0.03$ & $0.43 \pm 0.01$ & $0.51 \pm 0.01$ & $16.96 \pm 0.01$ & $1.2 \pm 0.01$ \\
\hline S4 & $23.61 \pm 0.01$ & $0.44 \pm 0.01$ & $0.537 \pm 0.03$ & $19.66 \pm 0.01$ & $1.24 \pm 0.01$ \\
\hline S5 & $24.21 \pm 0.02$ & $0.42 \pm 0.01$ & $0.532 \pm 0.01$ & $14.29 \pm 0.01$ & $1.16 \pm 0.01$ \\
\hline S6 & $24.16 \pm 0.03$ & $0.42 \pm 0.01$ & $0.49 \pm 0.01$ & & \\
\hline
\end{tabular}

*Each value represents mean \pm S.D $(n=3)$

Table 3: Post Compression Parameters

\begin{tabular}{|c|c|c|c|c|c|c|c|c|}
\hline Formulation & $\begin{array}{c}\text { Hardness } \\
\mathrm{Kg} / \mathrm{cm}^{2} \\
\end{array}$ & $\begin{array}{c}\begin{array}{c}\text { Thickness } \\
\text { mm }\end{array} \\
\end{array}$ & $\begin{array}{c}\text { Friability } \\
\% \\
\end{array}$ & $\begin{array}{c}\text { Avg. Weight } \\
\text { (mg) }\end{array}$ & $\begin{array}{c}\text { Content } \\
\text { uniformity }(\%) \\
\end{array}$ & $\begin{array}{c}\text { Wetting time } \\
\text { (sec) }\end{array}$ & $\begin{array}{c}\text { In vitro Dispersion } \\
\text { time (sec) }\end{array}$ & $\begin{array}{c}\text { Water Absorption } \\
\text { Ratio (\%) } \\
\end{array}$ \\
\hline $\mathrm{F} 1$ & $3.25 \pm 0.01$ & $3.1 \pm 0.01$ & $0.64 \pm 0.01$ & $100.12 \pm 0.03$ & $98.19 \pm 0.01$ & $147 \pm 0.02$ & $167 \pm 0.01$ & $41.6 \pm 0.01$ \\
\hline $\mathrm{F} 2$ & $3.26 \pm 0.01$ & $3.0 \pm 0.01$ & $0.69 \pm 0.01$ & $99.32 \pm 0.02$ & $97.23 \pm 0.01$ & $113 \pm 0.01$ & $90 \pm 0.02$ & $53.8 \pm 0.02$ \\
\hline F3 & $3.24 \pm 0.02$ & $2.9 \pm 0.02$ & $0.79 \pm 0.01$ & $99.57 \pm 0.01$ & $97.76 \pm 0.01$ & $91 \pm 0.01$ & $79 \pm 0.01$ & $74.6 \pm 0.01$ \\
\hline $\mathrm{F} 4$ & $3.11 \pm 0.02$ & $3.0 \pm 0.01$ & $0.94 \pm 0.01$ & $98.97 \pm 0.01$ & $97.89 \pm 0.04$ & $76 \pm 0.01$ & $51 \pm 0.01$ & $74.3 \pm 0.01$ \\
\hline F5 & $3.06 \pm 0.01$ & $2.7 \pm 0.02$ & $0.89 \pm 0.02$ & $98.68 \pm 0.03$ & $97.26 \pm 0.03$ & $59 \pm 0.02$ & $32 \pm 0.02$ & $79.8 \pm 0.04$ \\
\hline F6 & $2.97 \pm 0.01$ & $2.8 \pm 0.01$ & $0.97 \pm 0.03$ & $97.93 \pm 0.01$ & $97.48 \pm 0.02$ & $45 \pm 0.01$ & $24 \pm 0.01$ & $80.9 \pm 0.01$ \\
\hline FB6 & $3.02 \pm 0.03$ & $3.0 \pm 0.01$ & $0.84 \pm 0.02$ & $98.62 \pm 0.02$ & $99.18 \pm 0.02$ & $48 \pm 0.02$ & $26 \pm 0.03$ & $79.6 \pm 0.03$ \\
\hline $\mathrm{S} 1$ & $3.12 \pm 0.02$ & $3.2 \pm 0.01$ & $0.91 \pm 0.02$ & $97.21 \pm 0.01$ & $97.42 \pm 0.01$ & $148 \pm 0.01$ & $185 \pm 0.01$ & $39.6 \pm 0.02$ \\
\hline S2 & $3.08 \pm 0.01$ & $3.1 \pm 0.01$ & $0.89 \pm 0.01$ & $98.65 \pm 0.01$ & $98.09 \pm 0.01$ & $104 \pm 0.01$ & $98 \pm 0.04$ & $47.2 \pm 0.01$ \\
\hline $\mathrm{S} 3$ & $3.02 \pm 0.01$ & $2.8 \pm 0.02$ & $0.99 \pm 0.01$ & $96.32 \pm 0.01$ & $97.86 \pm 0.01$ & $95 \pm 0.01$ & $80 \pm 0.01$ & $56.3 \pm 0.01$ \\
\hline S4 & $3.16 \pm 0.02$ & $2.9 \pm 0.01$ & $0.85 \pm 0.01$ & $98.59 \pm 0.01$ & $98.01 \pm 0.01$ & $82 \pm 0.03$ & $67 \pm 0.03$ & $69.4 \pm 0.02$ \\
\hline S5 & $3.13 \pm 0.01$ & $3.2 \pm 0.01$ & $0.74 \pm 0.01$ & $98.76 \pm 0.01$ & $97.61 \pm 0.01$ & $73 \pm 0.01$ & $49 \pm 0.02$ & $76.3 \pm 0.01$ \\
\hline S6 & $3.07 \pm 0.01$ & $3.1 \pm 0.01$ & $0.67 \pm 0.01$ & $98.94 \pm 0.01$ & $98.02 \pm 0.01$ & $51 \pm 0.01$ & $36 \pm 0.01$ & $78.5 \pm 0.01$ \\
\hline SB6 & $3.11 \pm 0.01$ & $3.3 \pm 0.01$ & $0.73 \pm 0.01$ & $98.75 \pm 0.01$ & $98.89 \pm 0.01$ & $53 \pm 0.02$ & $39 \pm 0.01$ & $77.4 \pm 0.02$ \\
\hline
\end{tabular}

Table 4: Evaluation of Taste Masking Effect of Orodispersible Formulations

\begin{tabular}{|c|c|c|c|}
\hline Formulation Code & Average points by Volunteer & Acceptability & Rank \\
\hline Negative control & 99 & Very Good & 1 \\
\hline S6 & 90 & Very good & 2 \\
\hline F6 & 86 & Very good & 3 \\
\hline F5 & 84 & Good & 4 \\
\hline S4 & 83 & Good & 5 \\
\hline SB6 & 54 & acceptable & 6 \\
\hline Positive control & 19 & worst & 7 \\
\hline
\end{tabular}

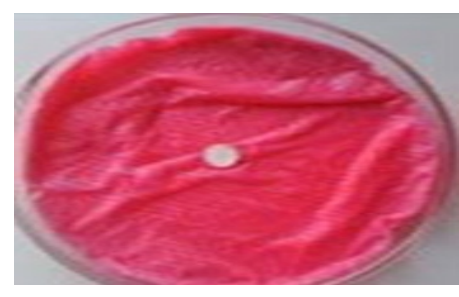

After 5 Sec

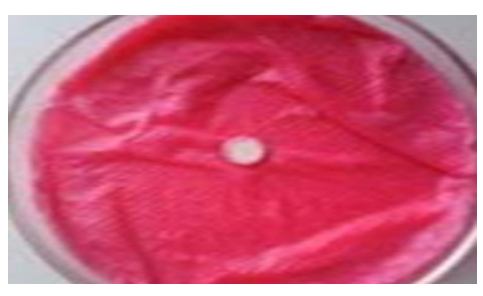

After 25 Sec

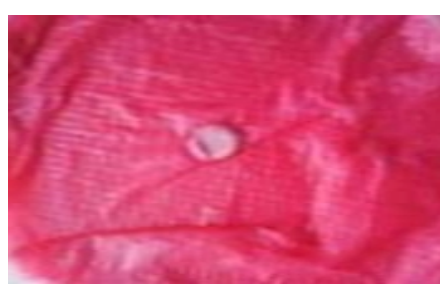

After 45 Sec

Figures 2: Wetting Time of Formulation $F_{6}$ 


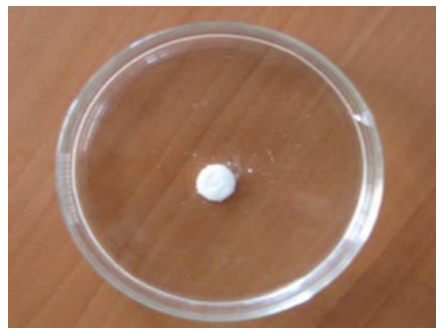

After 6 Sec

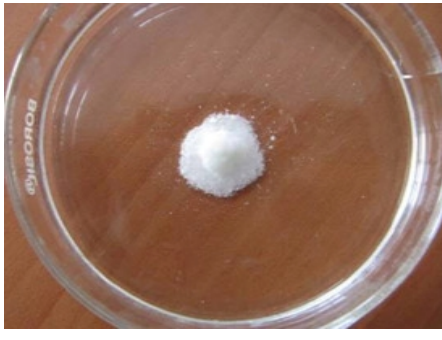

After 10 Sec

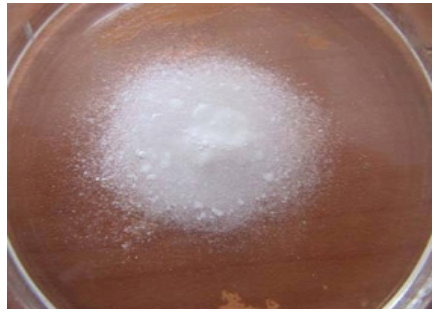

After 24 Sec

Figure 3: In-vitro Dispersion Time

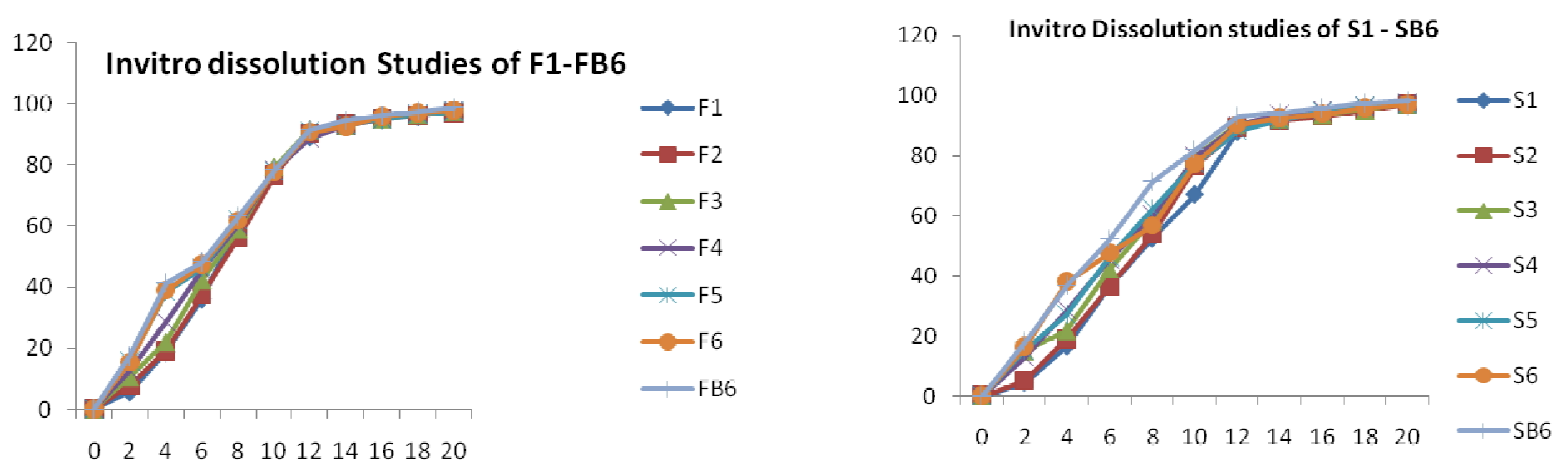

Figure 4: In-vitro Dissolution Studies of Formulations

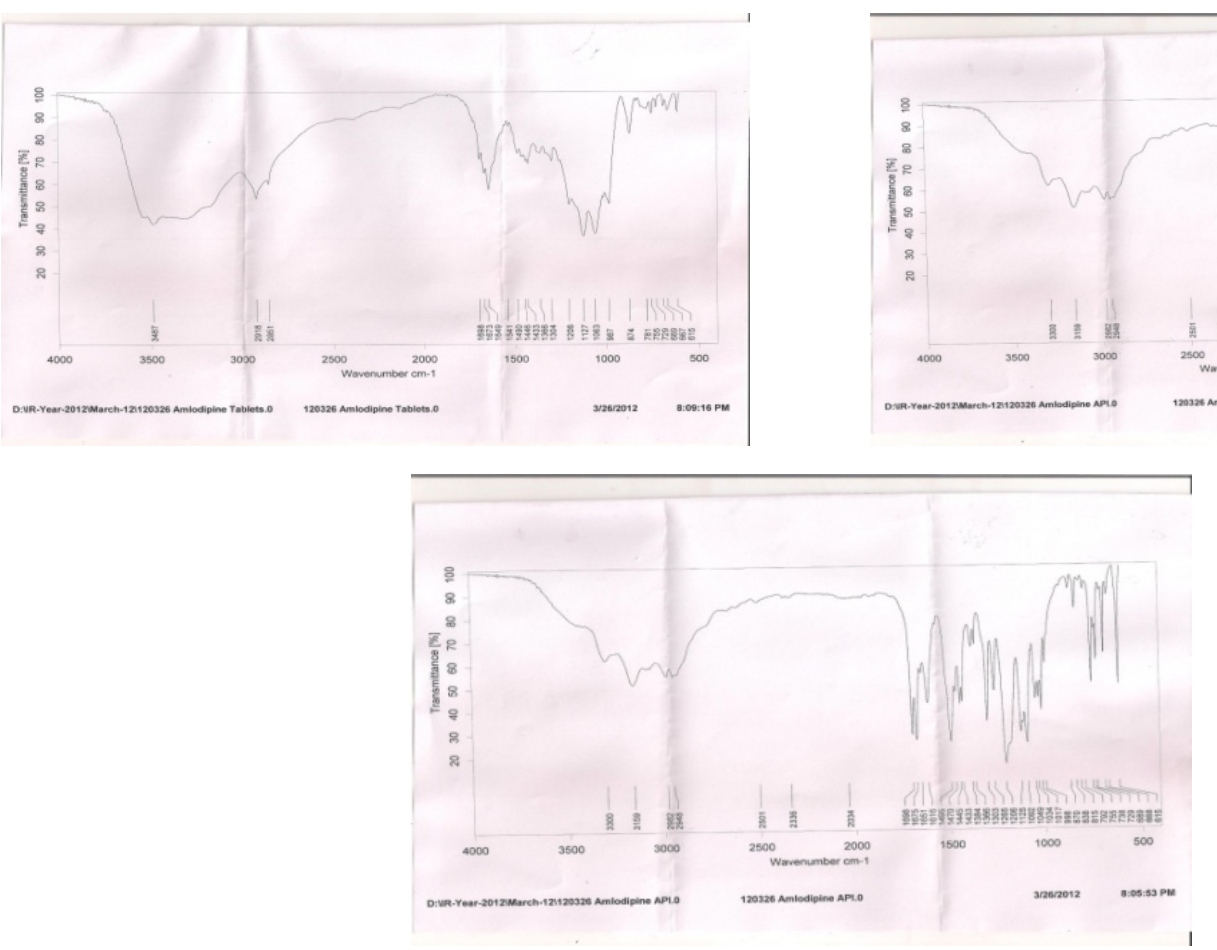

Figure 5: FTIR Spectroscopy of Pure Amlodipine Besylate Drug, $\mathrm{F}_{6}, \mathrm{~S}_{6}$ Tablet Formulations 


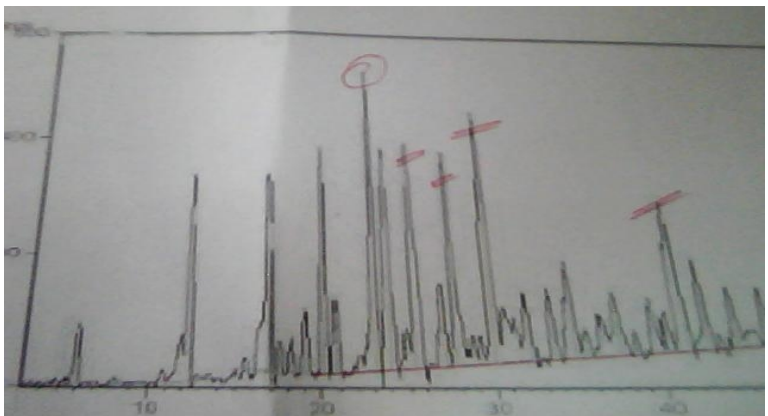

Pure Drug

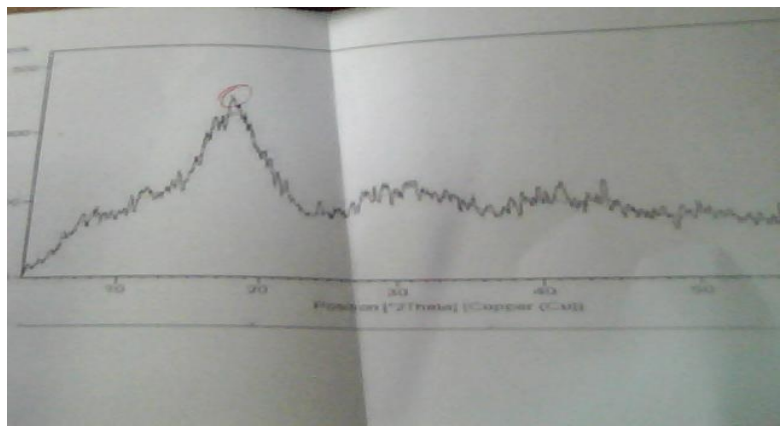

Eudragit EPO

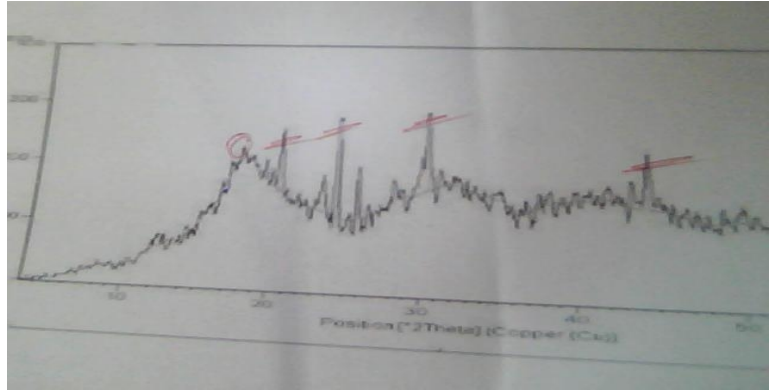

Eudragit EPO and D P C

Figure 6: X-Ray Diffraction Studies

Taste Evaluation

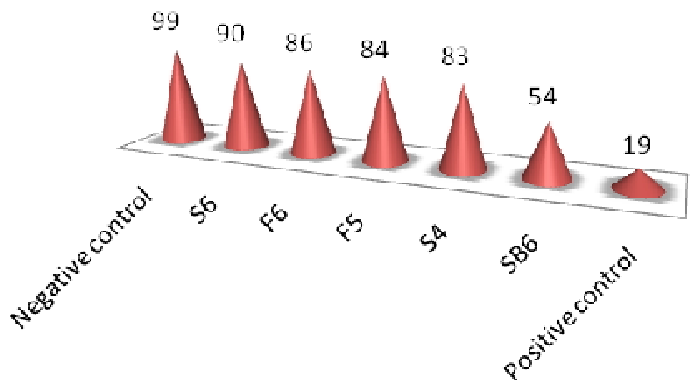

Figure 7: Taste Masking Effect of Orodispersible Formulations

\section{RESULTS}

Pre compressional Parameters

Table 2 shows the pre-compressional parameters of power blend. There was change in angle of repose from $F_{1}$ to $F_{6}$ and from $\mathrm{S}_{1}-\mathrm{S}_{6}$. Angle of repose increased from 23.29 to 23.89 and 23.12 to 24.2 respectively. Bulk Density and Tapped Density of all formulations are shown in the Table 2. The results indicated that both densities range from 0.41 to 0515 gm/c.c and 0.49 to $0.676 \mathrm{gm} / \mathrm{c} . \mathrm{c}$. \% Compressibility ranges from 11.76 to 23.71 and 14.03 to $19.66 \%$ in Kolloidan CL and Croscarmellose formulation respectively. All the formulations showed good and Fair flow properties.

\section{Post Compressional Parameters}

Hardness: Table 3 shows hardness of all tablet formulations. The results indicated that no such appreciable changes were observed with respect to hardness in all formulations form $\mathrm{F}_{1}$ to $\mathrm{F}_{6}$ and from $\mathrm{S}_{1}-\mathrm{S}_{6}$.

\% Friability: Table 3 shows the friability values of all tablet formulations. The results indicated that the \% friability of formulation was between $0.64 \%$ and $0.97 \%$. The low values of friability indicate that tablets were mechanically hard enough.

Thickness: Table 3 shows the thickness of all tablet formulations. The results indicated that the thickness of all formulations was between 3.45 to $3.95 \mathrm{~mm}$.

Weight Variation Test: Table 3 shows the average weight of all table formulations. The results indicated that average 
weight of all tablets formulations was between 96.32 to $100.12 \mathrm{mg}$.

\% Water Absorption Ratio: Table 3 shows \% water absorption ratio of all tablet formulation. The results indicated that formulation containing $1 \%$ Kollidon CL showed least water absorption. This may be due to less swelling property. \% water absorption ratio increases from $\mathrm{F} 1$ to F6 and from S1 to S6 as the concentration of kollidon CL and croscarmellose increases in tablet formulations.

Wetting Time: Table 3 show wetting studies. The results revealed that wetting studies of formulations $F_{2}$ to $F_{6}$ were significantly lower $(p<0.05)$ than $F_{1}$ (Figure $4 a, 4 b$ and $\left.4 c\right)$. Similarly wetting time of formulation $S_{2}$ to $S_{6}$ were significantly lower $(\mathrm{p}<0.05)$ than $\mathrm{S}_{1}$ (Figure 2$)$. It may be because capillary action was higher in all formulations $F 1$ to F6 and from S1 to S6 which absorbs water in higher amounts as concentrations Kollodion $\mathrm{CL}$ and Croscarmellose increases.

Drug Content of Tablets: Drug Content of tablets ranged between 97.23 to $99.18 \%$. Results are shown in Table 3 .

In-vitro Dispersion Time: The in-vitro dispersion times of formulations were in the range of $185-23 \mathrm{sec}$. Here we could clearly observe the effect of the concentration of the Kollidon CL and Croscarmellose Sodium concentration, as the concentration increased the dispersion time decreased. The concentration above 3\% showed very good results in Kollidon CL formulation and above $4 \%$ concentration in Croscarmellose sodium. And the formulations F4-F6 and S5S6 showed promising results for the ODT and at the same time the dispersion time of formulations is not effected by polymer complexation when compared with SB6 and FB6 (Figure 3).

In-vitro Release Studies: All the formulations were studied for In-vitro release studies. During this study all the formulations showed slight change in the dissolution rate initially. All the formulations could release $85 \%$ of the drug with in the 12 Minutes. When the formulations of F1-F5 when compared with FB6 the rate dissolution is not affected, F6 could release $90 \%$ of drug within 3 minutes and FB6 showed $90 \%$ of drug release in 10 minutes (approx). Similarly, when S6 and SB6 are compared S6 showed 90\% of drug release in 8 minutes (approx) and SB6 showed 90\% of drug release in 13 minutes (approx) (Figure 4).

FTIR Studies Data: The spectrum of pure Amlodipine Besylate and formulation F6, S6 are shown in (Figure 5). The FTIR spectrum of drug and polymer showed no significant shift or reduction in intensity of peaks of Amlodipine Besylate.

\section{X - Ray Diffraction}

The X-ray Diffractogram of pure Amlodipine Besylate, Eudragit EPO and drug polymer complex are shown in (Figure 6). The $\mathrm{x}$ ray diffraction confirms its crystalline nature as evidenced from number of sharp and intense peaks. The diffractogram of polymer (Eudragit EPO) showed diffused peak, indicating the amorphous nature while the diffraction pattern of drug polymer complex represents complete disappearance of crystalline peaks of drug especially those situated between $20^{\circ}$ and $600^{\circ}$. These finding suggest the formation of new solid phase with a lower degree of crystallinity due to complexation.

Human Taste Panel: The taste evaluation of Amlodipine Besylate was performed by volunteers in the age group of 18 to 22 yrs. The protocol was explained and written consent as obtained from volunteers. The formulations of Amlodipine Besylate were held in the mouth for 5 seconds by each volunteer. Bitterness levels were recorded instantly and then after 30 to $150 \mathrm{sec}$. The bitterness level was recorded as positive against Negative controls (Figure 7).

\section{DISCUSSION}

The demand for Oro dispersible tablets has enormously increased during the last decade, particularly for geriatrics and paediatrics patients who have difficulty in swallowing conventional tablets and capsules. Oral administration of the drugs is difficult in patients having concomitant vomiting or diarrhoea. Oro dispersible dosage forms are advantageous for such patients. Oro dispersible dosage forms are meant to dispersible immediately upon contact with the saliva leading to faster release of the drugs in the oral cavity. In the present work, mouth dissolving tablets of taste masked Amlodipine Besylate were prepared by direct compression. All the tablet formulations compressed individually using biconcave $6 \mathrm{~mm}$ punches in Rimek mini press 1, a 10 station rotary compression machine. Tablets were evaluated for changes in parameters by changing the concentration of superdisintegrants from 1 to $6 \%$ and Eudragit EPO used as taste masking agent. Precompressional parameters, angle of repose, \% compressibility and Hausner's ratio studies indicated that most of the formulations showed fair and good flow properties. Postcompressional parameters, hardness, friability, In-vitro Dispersion time, Wetting time, drug content and dissolution studies were studied. All the formulations showed no appreciable change in hardness, while friability of tablets ranged between $0.64 \%$ and $0.91 \%$. Drug Content of tablets ranged between 97.23 to $99.57 \%$. Invitro dispersion time, formulations containing $>5 \%$ Kollidon $\mathrm{CL}$ and $5 \%$ of Croscarmellose Sodium were found to be promising. The In-vitro dispersion time of Amlodipine Besylate tablets prepared by Kollidon CL was found to be in the range of 167-24 Seconds and for those of Croscarmellose Sodium was found to be in the range of 185-39 Seconds. Wetting time of promising formulations was found to be within 1 minute, which facilitates their faster dispersion in the mouth. Amongst the two super disintegrants used, namely, Kollidon CL and Croscarmellose Sodium, the Kollidon CL (6\%) superdisintegrant was found to be good. The 1:1 ratio of Eudragit EPO to drug was promising in masking the bitter taste of Drug. The In-vitro Dissolution studies states that formulations containing Eudragit EPO polymer didn't affected on rate of dissolution when compared with blank formulations. All the formulations showed $85 \%$ of drug release in $<12$ minutes. FTIR-spectroscopic studies indicated that there are no drug-excipient interactions. Similarly X-ray Diffraction studies suggested the formation of new solid phase with a lower degree of crystallinity due to complexation. From the results of present study indicates the complexation of Amlodipine Besylate and Eudragit EPO can not only mask its bitter taste significantly but also improve 
the dissolution profile. By employing direct compression method, Orodispersible tablets of $100 \mathrm{mg}$ weight with a taste acceptable to patients and sufficient structural integrity could be prepared. From all the superdisintegrants studied, tablets containing 6\% Kollidon CL gave the highest improvement in disintegration and dissolution profile of Amlodipine Besylate.

\section{ACKNOWLEDGEMENT}

The author was thankful to all people for providing necessary facilities and extended support to carry out research work.

\section{REFERENCES}

1. Mishra DN, Bindal M, Singh SK, Kumar SGV. Spray Dried Excipient Base: A Novel Technique for the Formulation of Orally Disintegrating Tablets. Chem. Pharm. Bull 2006; 54(1): 99-102. http://dx.doi.org/ $10.1248 / \mathrm{cpb} .54 .99$

2. Arjun G, Prasad M, Santosha D, Achaiah G. Formulation and Evaluation of Rosiglitazone mouth dissolving tablet. Int J Pharm. Bio. Sci 2010; 1: 45-49.

3. Seager H. Drug Delivery Products and Zydis Fast dissolving Dosage Form. J Pharm. Pharmacol 1998; 50(4): 375-382. http://dx.doi.org/ 10.1111/j.2042-7158.1998.tb06876.x PMid:9625481

4. Ciper M, Bodmeier R. Modified conventional hard gelatin capsules as fast disintegrating dosage form in the oral cavity. Eur J Pharm Biopharm 2006; 62(2): 178-184. http://dx.doi.org/10.1016/j.ejpb.2005.08.014 PMid: 16260126

5. Suresh B, Rajendar KM, Ramesh G, Yamsani MR. Orodispersible tablets: An overview. Asian J Pharm 2008; 2(1): 2-11. http://dx.doi.org $/ 10.4103 / 0973-8398.41557$

6. Dobetti L. Fast-Melting Tablets: Developments and Technologies Pharma Tech 2001; (21Suppl.): 44-50.

7. Koizumi K, Watanabe Y, Monita K, Utosuchi N. New method of preparing high-porosity rapidly saliva soluble compressed tablets using mannitol with camphor, a subliming material. Int J Pharm 1997; 152(1): 127-131. http://dx.doi.org/10.1016/S0378-5173(97)04924-7

8. Yourong Fu, Shicheng Yang, Seong Hoon Jeong, Susumu Kimura, Kinam Park. Crit. Rev. Ther. Drug Carrier Syst 2004; 21(6): 433-476. http://dx.doi.org/10.1615/CritRevTherDrugCarrierSyst.v21.i6.10 PMid: 15658933

9. Ahmed IS, Aboul Einien MH. In vitro and In vivo evaluation of a fastdisintegrating lyophilized dry emulsion tablet containing Griseofulvin. Eur. J Pharm Sci 2007; 32(1): 58-68. http://dx.doi.org/10.1016/ j.ejps.2007.05.114 PMid:17628451

10. Biradar SS, Bhagavati ST, Kuppasad IJ. Orodispersible tablets: An overview. Int. J Pharmacol 2006; 4(2): 21-27.

11. Omaima A, Sammour, Mohammed A, Hammad Nagia A, Megrab Ahmed S. Zidan. Formulation and optimization of mouth dissolve tablets containing Rofecoxib solid dispersion. AAPS Pharm. Sci. Tech 2006; 7(2): 55-58.

12. Suresh S, Pandit V, Joshi HP. A HPTLC method for quantitative estimation of swetiamarin in marketed polyherbal antidiabetic formulations Indian J Pharm Sci 2007; 69(3): 467-469. http://dx.doi.org /10.4103/0250-474X.34568

13. Bolhuis GK, Zurman K, Wierik GHP. Improvement of dissolution of poorly soluble drugs by solid deposition on a super disintegrant. II. The choice of super disintegrants and effect of granulation. Eur. J Pharm. Sci 1997; 5(2): 63-69. http://dx.doi.org/10.1016/S0928-0987(96)00256-4
14. Patel M, Patel N, Patel M. Formulation design and optimization of mouth dissolve tablets of Etorocoxib using vacuum drying technique. Drug Del Technol 2007; 7(2): 33-38.

15. Ahmed IS, Fatahalla FA. Pilot Study of Relative Bioavailability of Two Oral Formulations of Ketoprofen $25 \mathrm{mg}$ in Healthy Subjects. A FastDissolving Lyophilized Tablet as Compared to Immediate Release Tablet. Drug Develop. Ind. Pharm 2007; 33(5): 505-511. http://dx. doi.org/10.1080/03639040601150237 PMid:17520441

16. Gohel M, Patel M, Amin A, Agrawal R, Dave R, Bariya N. Formulation design and optimization of mouth dissolve tablets of nimesulide using vacuum drying technique. AAPS Pharm. Sci. Tech 2004; 5(3): 10-15. http://dx.doi.org/10.1208/pt050336PMid:15760070 PMCid:PMC2750260

17. Ahmed IS, Nafadi MM, Fatahalla FA. Formulation of a Fast-Dissolving Ketoprofen Tablet Using Freeze-Drying in Blisters Technique. Drug Develop Ind Pharm 2006; 32(4): 437-442. http://dx.doi.org/10.1080 /03639040500528913 PMid:16638681

18. Indurwade NH, Rajyaguru TH, Nahat PD. Novel approach- fast dissolving tablets. Indian Drugs 2002; 39(8): 405-409.

19. Shu T, Suzuki H, Hironaka K. Studies of Rapidly Disintegrating Tablets in the Oral Cavity Using Co-ground Mixtures of Mannitol with Crospovidone . Chem. Pharm. Bull 2002; 50(2): 193-198. http://dx. doi.org/10.1248/cpb.50.193

20. Patel HA, Patel JK, Patel KN and Patel RR. Studies on Formulation and In vitro Evaluation of Fast Dissolving Tablets of Domperidone. Indian J Pharm Sci 2010; 2(1): 470-476.

21. RK Chang, X Guo, BA Burnside, RA Couch. Formulation and evaluation of fast dissolving tablets of cinnarizine using superdisintegrants.Pharmaceutical Technology 2000; 24(6): 52-58.

22. Mahajan HS, Patil SB and Gattani SG. Rapidly disintegrating tablets for elderly patients. The Pharma Review 2005; 3: 49-51.

23. Pebley WS, Jager NE and Thompson SJ. Rapidly disintegrating tablets, US Patent No. 5,298,261; 1994.

24. Allen LV and Wang B. Method of making a rapidly dissolving tablet, US Patent No. 5,635,210; 1997.

25. Knistch KW. Production of porous tablets, US Patent No. 4,134,843; 1979.

26. Roser BJ and Blair J. Rapidly soluble oral dosage form: Method of making same and composition, US Patent No. 5, 762,961; 1998.

27. Lachman L, Lieberman A and Kinig JL. The Theory and Practice of Industrial Pharmacy, $4^{\text {th }}$ ed, Varghese Publishing House, Bombay; 1991. p. $67-68$

28. Battue SK, Repay MA, Maunder S and Rio MY, Formulation and evaluation of rapidly disintegrating tablet Fenoverine tablets: Effect of superdisintegrants, Drug Dev Ind. Pharm 2007; 33(11): 1225-1232. http://dx.doi.org/10.1080/03639040701377888 PMid:18058319

29. Ashiqul Islam, Syed Shabbir Haider and Md Selim Reza. Formulation and Evaluation of Orodispersible Tablet of Domperidone. Dhaka Univ. J. Pharm. Sci 2011; 10(2): 117-122.

30. J Wells. Pharmaceutical preformulation, the physicochemical properties of drug substances, in Pharmaceutics - the Science of Dosage Form Design, $2^{\text {nd }}$ ed. (Ed. ME Aulton), Churchill Livingstone, London; 2002. p. $113-138$

Cite this article as:

B. Sree Giri Prasad, V.R.M Gupta, N. Devanna, N. Siva Subramanian, CH. Naveen Kumar, CH. Maheswar Reddy. Formulation and evaluation of taste masked orodispersible tablets of amlodipine besylate by direct compression. Int. Res. J. Pharm. 2013; 4(7): 123-130 http://dx.doi.org/10.7897/2230$\underline{8407.04728}$ 